\title{
Assessment of environmental impact of coarse aggregates substitution by crushed pavements in concrete mixtures
}

\author{
Jan Kočí1, ${ }^{1,}$, Jan Fořt ${ }^{1}$, Václav Kočí ${ }^{1}$ and Izabela Hager $^{2}$ \\ ${ }^{1}$ Czech Technical University in Prague, Department of Materials Engineering and Chemistry, \\ Faculty of Civil Engineering, Thákurova 7/2077, 16629 Prague 6, Czech Republic \\ ${ }^{2}$ Cracow University of Technology, Building Materials Engineering, Faculty of Civil Engineering, \\ 24 Warszawska St., 31-155 Cracow, Poland
}

\begin{abstract}
Inefficient use of end-of-life materials in combination with depletion of primary sources can be understood as a significant factor that motivates to effective waste material recycling and reuse. Since the construction industry produces millions of tons of building materials, which are continuously reaching their service life end, there is a great potential for their reuse instead of simple landfilling. In this light, concrete is a versatile building material that might incorporate lots of recycled building materials as it is demanding on primary sources. A substitution of coarse aggregates by recycled products is, therefore, one of the ways how to mitigate these environmental burdens. This paper aims at evaluation of environmental contributions of concrete with coarse aggregates being substituted by crushed concrete pavements. Various amounts of recycled aggregates were assumed $(0 \%, 50 \%$, and $100 \%)$ to reveal the environmental impacts. The analysis incorporates all inputs and outputs related to the production of concrete and recycling of concrete pavements (raw materials production, processing, transport emissions, energy production, etc.). The results indicate that substitution of coarse aggregates by recycled concrete pavements may bring significant mitigation of environmental impacts and hence it deserves further investigation.
\end{abstract}

\section{Introduction}

Since the concrete is the most used building material worldwide, the extensive development in urbanism increase the negatives accompanied by the cement production [1]. The annual production of concrete exceeded by far 15 billion tons and still growing. The effort paid on replacement of Portland cement partially succeeds, but on the other hand, the concrete production requires an enormous amount of aggregates. However, the availability of such materials is limited especially when concerning the local abundance since the transportation of a large volume of aggregates from remote sites cannot be viewed as viable either from the economic nor environmental point of view [2,3]. On top

\footnotetext{
* Corresponding author : jan.koci@ fsv.cvut.cz
} 
of that, performed prediction estimates that demand for aggregate will double within the upcoming decade thus can pose a barrier for the construction industry [4].

Particular problems related to extensive sand use for concrete production lay in the substantial depletion of natural resources and irreversible changes in the natural environment. On this account, substantial efforts are paid on the preservation of virgin materials by increased recycling of various waste materials. Namely, the construction industry produces millions of tons of building materials, which have great potential for further utilization instead of landfilling [3]. Moreover, waste landfilling became an undesirable way to waste disposal and new destinations for various waste materials need to be defined.

Hence, several researchers aimed their attention to the reuse of various waste material in concrete production to preserve natural resources [6-8]. Among others, recycled concrete, ceramic tiles, bricks, and many others were extensively studied from the functional point of view as alternatives for fine or coarse aggregates. The motivation was often driven by the potential cost savings accompanied by the saved landfill fees. In addition to the improved economic viability, the environmental impact became one of the most important factors when taking into account long-term implications as well as various national strategies related to construction and demolition waste (CDW) disposal. In this context, CDW represents a major problem that needs to be resolved since the CDW accounts for almost $40 \%$ of the total solid waste produced in the EU [9].

Considering the transition to the circular economy, the efficiency of such endeavors needs to be clearly described to avoid misleading efforts. In this sense, the inclusion and precise evaluation of all manufacturing processes need to be taken into account and quantified by life cycle assessment (LCA) as an efficient and comparable tool for the recycling strategy [10].

This paper provides the analysis of environmental implications driven by the partial and complete replacement of natural aggregates by crushed concrete pavements. For a coherent environmental analysis, the life cycle assessment methodology was chosen in order to provide comparable outputs. The data used were taken from the Simapro LCA software 8.5 and Ecoinvent database v3.5.

\section{Materials and methodology}

This study accesses the environmental analysis of used concrete pavements as an aggregate for the design of modified concrete mixtures by the LCA methodology [11, 12]. The chosen approach allows comparative environmental analysis of each manufacturing step and quantification of obtained benefits accordingly to EN 14010 and EN 14044 standards. The LCA analysis in this paper was done in the following steps:

\subsection{Goal of the study and functional unit definition}

The main objective of the performed work consists of the environmental assessment of reference concrete mixture prepared from virgin resources and comparison with alternative scenarios with crushed concrete pavements as 50\% and $100 \%$ replacement of natural aggregates. The used end-of-life concrete pavement blocks are depicted in Figure 1. The detailed description of mixtures composition is given in Table 1. The functional unit selected for this study was defined as $1 \mathrm{~m}^{3}$ of a produced concrete mixture. 


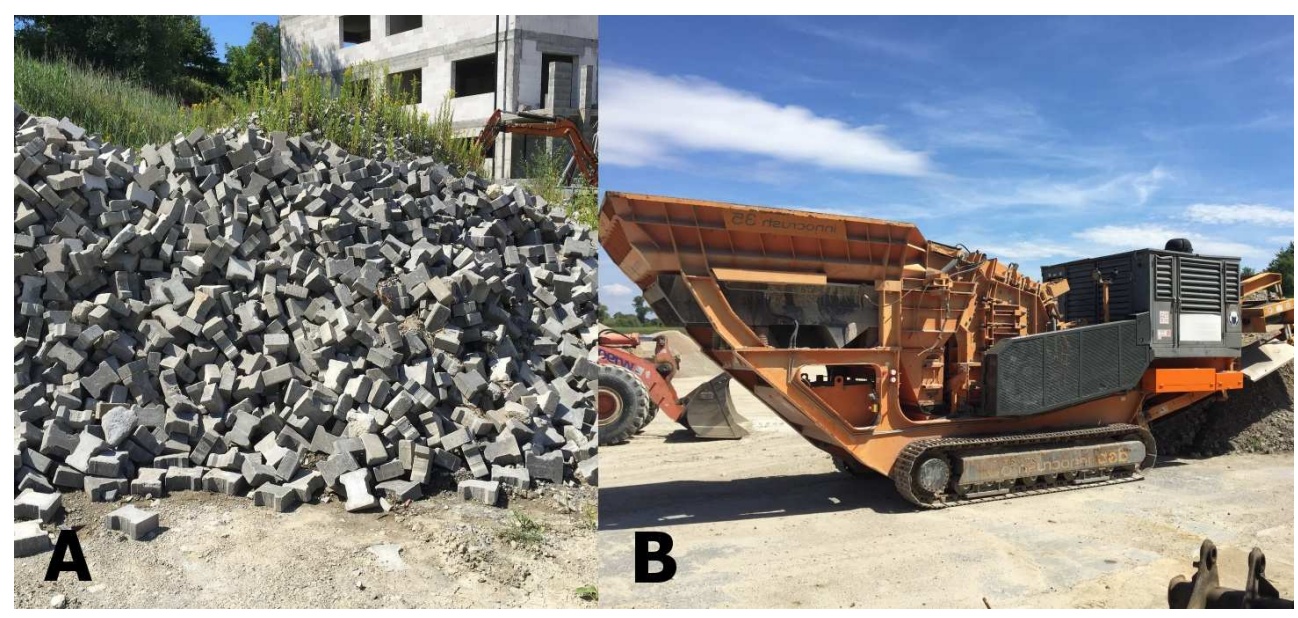

Fig. 1. A - End-of-life concrete pavement blocks, B - processing of pavement blocks

Table 1. Composition of studied concrete mixtures

\begin{tabular}{|l|c|c|c|}
\hline & OC & RAC 50 & RAC 100 \\
\hline CEM I 42.5 R & 414.2 & 414.2 & 414.2 \\
\hline w/c & 0.45 & 0.45 & 0.45 \\
\hline River sand 0/4 mm & 615.1 & 280.6 & 569.2 \\
\hline Coarse agg. 2/8 mm & 579.9 & 280.6 & - \\
\hline Coarse agg. 8/16 mm & 562.3 & 264.1 & - \\
\hline Recycled concrete agg. 4/16 mm & - & 825.3 & 1057.2 \\
\hline Plasticizer BASF BV 18 & 0.9 & 0.9 & 0.9 \\
\hline Basf Glenium SKY 591 & 1.4 & 1.4 & 1.4 \\
\hline
\end{tabular}

\subsection{System boundaries and limitations}

In this study, two scenarios of concrete pavement recycling in the concrete mixture were considered. First, 50\% replacement of 2/8 $\mathrm{mm}$ and $8 / 16 \mathrm{~mm}$ aggregates, while the second scenario contemplates complete replacement of natural aggregates by crushed pavement blocks. The detailed information regarding the boundary conditions and particular processes involved are described in Fig. 2. 


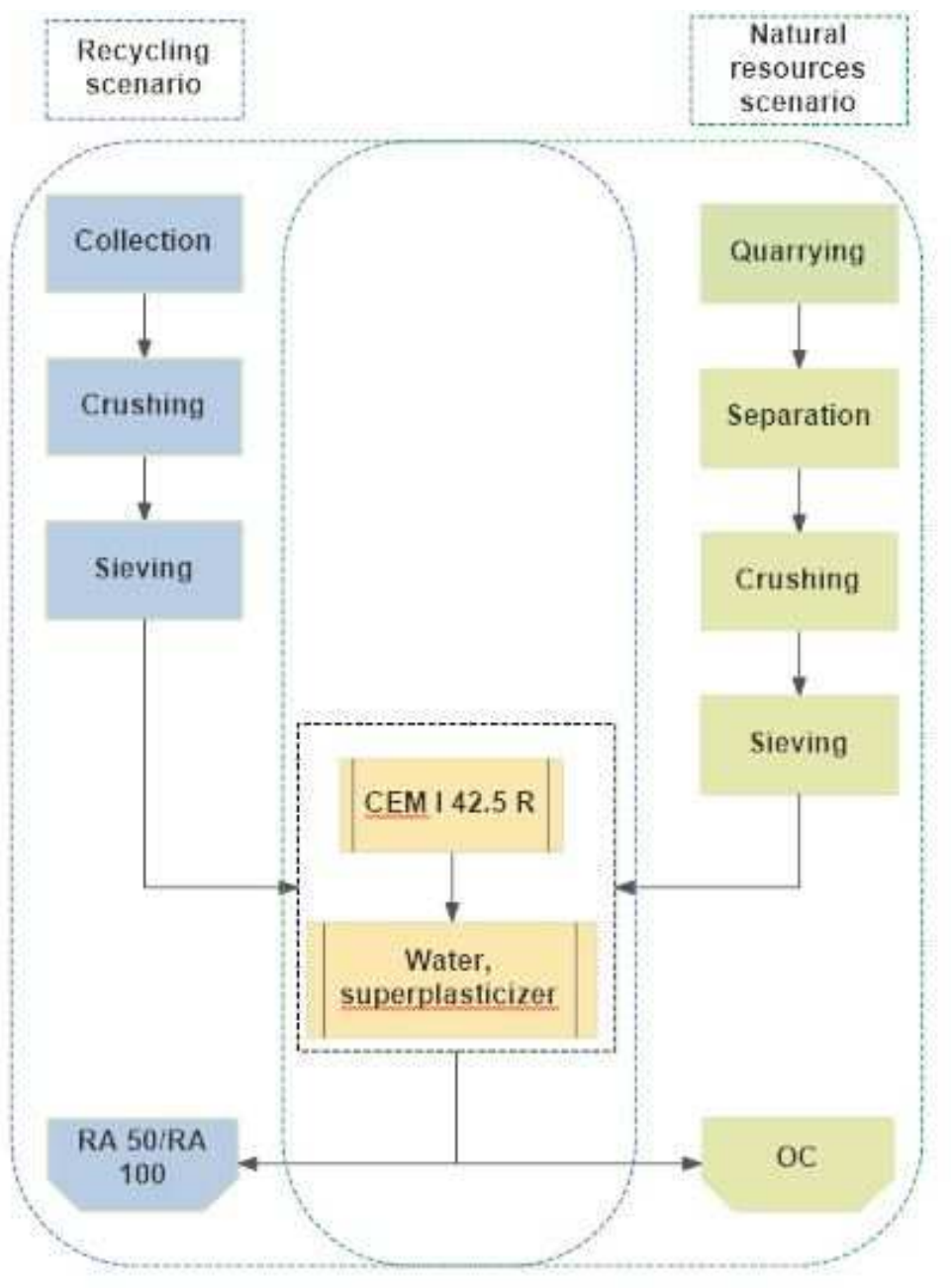

Fig. 2. Scheme of involved processes.

\subsubsection{Natural resources scenario}

Processing of natural aggregates in this scenario is based on quarrying of granite/limestone, loading, two-stage crushing, loading, and transportation between particular stages. Transportation distances for natural aggregate were $30 \mathrm{~km}$ according to Borghi et al. [9].

\subsubsection{Recycling scenario}

The end-of-life pavements blocks remain usually discarded and landfilled. In this study, the pavement blocks are collected, crushed, sieved, transported to a concrete plant, and utilized as a replacement of natural aggregates. For this scenario, the material needs to be transported about $60 \mathrm{~km}$ together including collection and consequent delivery to the concrete plant. 


\subsection{Life cycle impact assessment}

The LCIA based on the IMPACT 2002 + methodology, was used, often employed by other researchers to evaluate the LCA of building materials. The following midpoint impact indicators were measured: Carcinogens, non-carcinogens (NCA), respirátory inorganics (RI), ionizing radiation (RI), ozone layer depletion (OLD), respiratory organics (RO), aquatic ecotoxicity (AE), terrestrial ecotoxicity (TE), terrestrial acidification/nitrification (TA/N), land occupation (LO), aquatic acidification (AC), aquatic eutrophication (AEU), global warming (GW), non-renewable energy (NRE), mineral extraction (ME). All the data collected to develop the study were directly obtained using SW - Simapro 8.5 software to compile the inventory data and to perform the impact assessment. Ecoinvent database 3.5 was employed.

\section{Results and discussion}

The visual comparison of a particular scenario is plotted in Fig. 3 for each midpoint impact indicator. As one can see, in almost all monitored indicators, the utilization of crushed waste pavement blocks resulted in notable improvements. Namely, the most favorable results were reached for a reduction in aquatic eutrophication and terrestrial acidification/nitrification. A substantial decrease in mineral extraction refers to the preservation of natural resources thanks to waste material valorization. When comparing both alternative scenarios for the pavement reuse, the complete replacement of coarse aggregates provides more favorable results that can be assigned to more demanding processing. Considering the calculated results for global warming by the meaning of the carbon dioxide equivalent, all scenarios achieved similar values and only minor improvement was delivered. The required processing, crushing in particular, requires substantial energy input, thus negatively affects the results. On the other hand, only a few indicators refer to an increased negative impact on the natural environment. As concluded by Borghi et al. [9], the replacement of aggregates in concrete does not provide a significant reduction in carbon dioxide production since the longer transportation distance shifted the diesel consumption. The enumerated results for each scenario are given in Table 2 for a better understanding and a more detailed overview. 


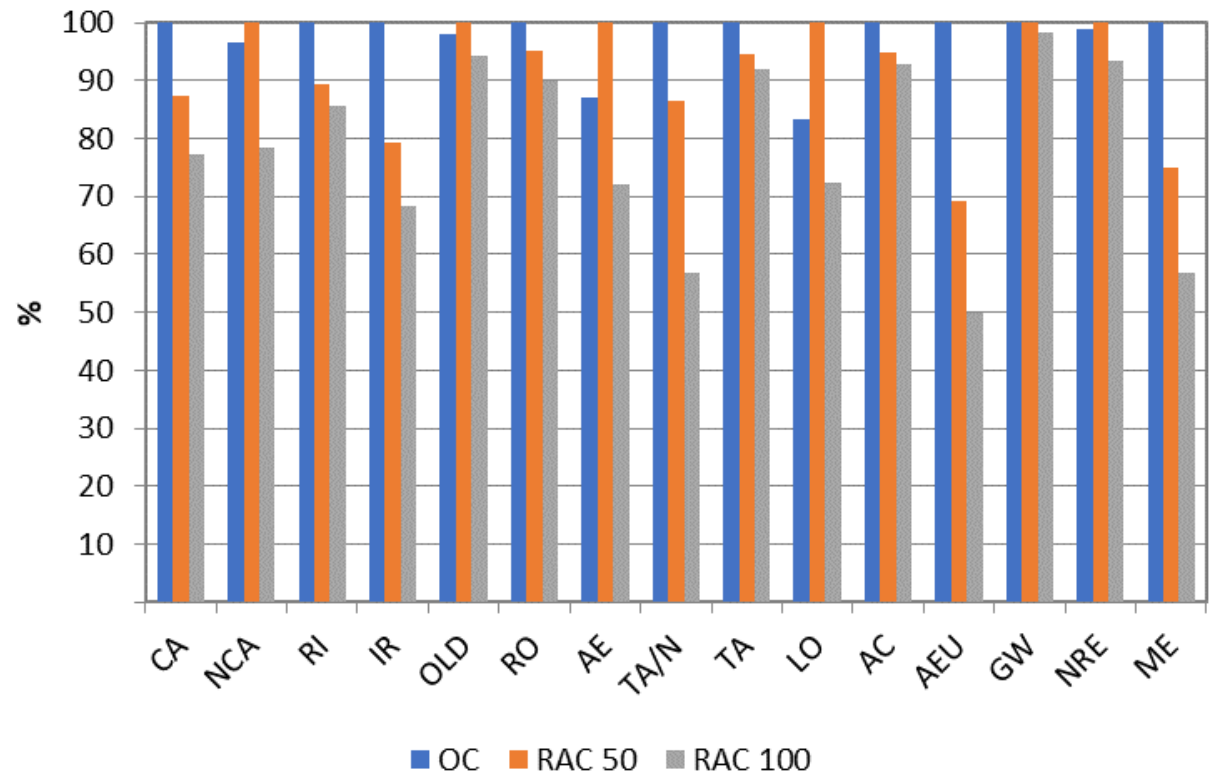

Fig. 3. Percentual comparison of calculated midpoint indicators

Table 2. Calculated values of selected midpoint indicators

\begin{tabular}{|c|c|c|c|c|}
\hline Impact category & Unit & OC & RAC 50 & RAC 100 \\
\hline Carcinogens & $\mathrm{kg} \mathrm{C}_{2} \mathrm{H}_{3} \mathrm{Cl}$ eq & 0.207928 & 0.181762 & 0.160954 \\
\hline Non-carcinogens & $\mathrm{kg} \mathrm{C}_{2} \mathrm{H}_{3} \mathrm{Cl}$ eq & 0.376624 & 0.38956 & 0.305319 \\
\hline Respiratory inorganics & $\mathrm{kg} \mathrm{PM}_{2.5} \mathrm{eq}$ & 0.080252 & 0.071736 & 0.06861 \\
\hline Ionizing radiation & $\mathrm{Bq} \mathrm{C}^{-14} \mathrm{eq}$ & 384.3772 & 304.4095 & 262.7194 \\
\hline Ozone layer depletion & $\mathrm{kg} \mathrm{CFC}^{-11}$ eq & $9.86 \mathrm{E}-06$ & $1.01 \mathrm{E}-05$ & $9.47 \mathrm{E}-06$ \\
\hline Respiratory organics & $\mathrm{kg} \mathrm{C}_{2} \mathrm{H}_{4} \mathrm{eq}$ & 0.032686 & 0.031078 & 0.029436 \\
\hline Aquatic ecotoxicity & kg TEG water & 1235.46 & 1418.594 & 1020.719 \\
\hline Terrestrial ecotoxicity & kg TEG soil & 915.9246 & 793.493 & 521.3207 \\
\hline Terrestrial acid/nutri & $\mathrm{kg} \mathrm{SO}_{2} \mathrm{eq}$ & 2.37292 & 2.243352 & 2.181528 \\
\hline Land occupation & $\mathrm{m}^{2}$ org.arable & 0.936772 & 1.125691 & 0.813272 \\
\hline Aquatic acidification & $\mathrm{kg} \mathrm{SO}_{2} \mathrm{eq}$ & 0.48918 & 0.463767 & 0.453614 \\
\hline Aquatic eutrophication & $\mathrm{kg} \mathrm{PO}_{4} \mathrm{P}-\mathrm{lim}$ & 0.002552 & 0.001765 & 0.001274 \\
\hline Global warming & $\mathrm{kg} \mathrm{CO}_{2} \mathrm{eq}$ & 168.6626 & 168.5723 & 165.6829 \\
\hline Non-renewable energy & MJ primary & 807.8142 & 816.8235 & 762.527 \\
\hline Mineral extraction & MJ surplus & 0.686285 & 0.514924 & 0.390787 \\
\hline
\end{tabular}




\section{Conclusions}

In this study, we accessed the comparison of two alternative scenarios for coarse aggregate replacement by end-of-life pavement blocks and consequent concrete design by the meaning of the life cycle assessment. Revealed results refer to the mitigation of environmental externalities accompanied by traditional concrete production. The most significant improvement was obtained for mineral extraction. This approach complies with the transition towards a circular economy model based on the valorization of the end-of-life- materials and substantial reduction of the produced waste. Since the availability of concrete aggregates became limited in several European countries, the broader utilization of waste products may overcome this deficit and provide a favorable way in terms of sustainable development.

This research has been supported by the Grant Agency of the Czech Technical University in Prague under project No. SGS19/143/OHK1/3T/11 and by EMMAT project E-mobility and sustainable materials and technologies PPI/APM/2018/00027 financed by the Polish National Agency for Academic Exchange (NAWA).

\section{References}

1. S. A. Miller, V. M. John, S. A. Pacca, A. Horvath, Cem. Concr. Res. 114, 115-124 (2008)

2. Y. R. Zhang, W. Luo, J. J. Wang, Y. F Wang, Y. Q. Xu, J. Z. Xiao, Constr. Build. Mater. 209, 115-125 (2019)

3. M. Ghanbari, A. M. Abbasi, M. Ravanshadnia, J. Mater. Cycles Waste 20 (2), 810$822(2018)$

4. T. Sonderegger, J. Dewulf, P. Fantke, D. M. de Souza, S. Pfister, F. Stoessel, F. Verones, M. Vieira, B. Weidema, S. Hellweg, Int. J. Life Cycle Assess. 22 (12), 1912-1927 (2017)

5. M. A. Reuter, A. van Schaik, J. Gutzmer, N. Bartie, A. Abadias-Llamas, In Ann. Rev. Mater. Res. 49, 253-274 (2019)

6. L. Horckmans, P. Nielsen, P. Dierckx, A. Ducastel, Resour. Conserv. Recy 140, 297-304 (2019)

7. G. Azua, M. Gonzalez, P. Arroyo, Y. Kurama, J. Clean. Prod. 210, 1425-1434 (2019)

8. J. Fort, R. Novotny, E. Vejmelkova, A. Trnik, P. Rovnanikova, M. Keppert, V. Pommer, R. Cerny, J. Mat. Res. Technol. 8 (6), 6253-6261 (2019)

9. G. Borghi, S. Pantini, L. Rigamonti, J. Clean. Prod. 184, 815-825 (2018)

10. L. A. L. Ruiz, X. R. Ramon, S. G. Domingo, J. Clean. Prod. 248, 15 (2020)

11. M. A. Pedreno-Rojas, J. Fort, R. Cerny, P. Rubio-de-Hita, J. Clean. Prod. 253 (2020)

12. J. Fort, R. Cerny, J. Clean. Prod. 177, 795-802 (2018) 